TI 2011-113/3

Tinbergen Institute Discussion Paper

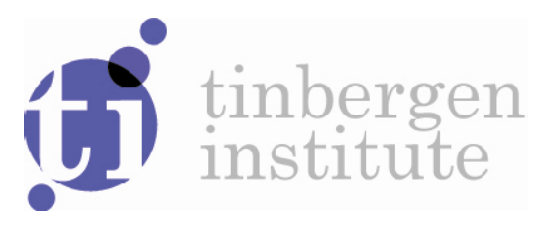

\title{
A Stepwise Projection Data Envelopment Analysis for Public Transport Operations in Japan
}

Soushi Suzukil

Peter Nijkamp²

1 Hokkai-Gakuen University, Sapporo, Japan;

2 VU University Amsterdam, and Tinbergen Institute. 
Tinbergen Institute is the graduate school and research institute in economics of Erasmus University Rotterdam, the University of Amsterdam and VU University Amsterdam.

More TI discussion papers can be downloaded at http://www.tinbergen.nl

Tinbergen Institute has two locations:

Tinbergen Institute Amsterdam

Gustav Mahlerplein 117

1082 MS Amsterdam

The Netherlands

Tel.: +31(0)205251600

Tinbergen Institute Rotterdam

Burg. Oudlaan 50

3062 PA Rotterdam

The Netherlands

Tel.: +31(0)10 4088900

Fax: $+31(0) 104089031$

Duisenberg school of finance is a collaboration of the Dutch financial sector and universities, with the ambition to support innovative research and offer top quality academic education in core areas of finance.

DSF research papers can be downloaded at: http://www.dsf.nl/

Duisenberg school of finance

Gustav Mahlerplein 117

1082 MS Amsterdam

The Netherlands

Tel.: +31(0)20 5258579 


\title{
A Stepwise Projection Data Envelopment Analysis for Public Transport Operations in Japan
}

\author{
Soushi Suzuki $^{\mathrm{a}} \quad$ Peter Nijkamp $^{\mathrm{b}}$ \\ ${ }^{a}$ Hokkai-Gakuen University, Department of Civil and Environmental Engineering, South26-West 11,1-1,chuo-ku, 064-0926 Sapporo, Japan \\ ${ }^{\mathrm{b}}$ VU University Amsterdam, Department of Spatial Economics, De Boelelaan 1105, 1081 HV Amsterdam, The Netherlands
}

\begin{abstract}
With tightening budgets and increasingly critical reviews of public expenditure, there is a need for a careful analysis of the performance of public bodies in terms of an efficient execution of their tasks. These questions show up everywhere in the public domain, for instance, in the provision of medical facilities, the operation of postal services, or the supply of public transport. A standard tool to judge the efficiency of such agencies is Data Envelopment Analysis (DEA). In the past years, much progress has been made to extend this approach in various directions. Examples are the Distance Friction Minimization (DFM) model and the Context-Dependent (CD) model.

The DFM model is based on a generalized distance friction function and serves to improve the performance of a Decision Making Unit (DMU) by identifying the most appropriate movement towards the efficiency frontier surface. Standard DEA models use a uniform proportional input reduction (or a uniform proportional output increase) in the improvement projections, but the DFM approach aims to enhance efficiency strategies by introducing a weighted projection function. This approach may address both input reduction and output increase as a strategy of a DMU. A suitable form of multidimensional projection functions is given by a Multiple Objective Quadratic Programming (MOQP) model using a Euclidean distance. Likewise, the CD model yields efficient frontiers in different levels, while it is based on a level-by-level improvement projection.

The present paper will first offer a new integrated DEA tool - emerging from a blend of the DFM and CD model using the Charnes-Cooper-Rhodes (CCR) method - in order to design a stepwise efficiency-improving projection model for a conventional DEA. The above-mentioned stepwise-projection model is illustrated on the basis of an application to the efficiency analysis of public transport operations in Japan.
\end{abstract}

Keywords: Data Envelopment Analysis (DEA), Stepwise projection, Distance Friction Minimization, Context-dependence, public transport operations

*Corresponding author: Soushi Suzuki (e-mail address: soushi-s@cvl.hokkai-s-u.ac.jp) 


\section{Introduction}

With tightening budgets and increasingly critical reviews of public expenditure, there is a need for a careful analysis of the performance of public bodies in terms of an efficient execution of their tasks. These questions show up everywhere in the public domain, for instance, in the provision of medical facilities, the operation of postal services, or the supply of public transport.

A standard tool to judge the efficiency of such agencies is Data Envelopment Analysis (DEA). DEA has gained much importance in economic performance studies. Seiford (2005) mentions some 2800 published articles on DEA. This large number of studies shows that comparative efficiency analysis has become an important topic in both the private and public sector. DEA was developed to analyze the relative efficiency of agents or decision makers, in general, Decision Making Unit (DMU), by constructing a piecewise linear production frontier, and projecting the performance of each DMU onto the frontier. A DMU that is located on the frontier is efficient, while a DMU that is not on the frontier is inefficient. An inefficient DMU can become efficient by reducing its inputs or increasing its outputs. In the standard DEA approach, this is achieved by a uniform reduction in all inputs (or a uniform increase in all outputs). But in principle, there are an infinite number of improvements to reach the efficient frontier, and hence there are many solutions for a DMU to enhance efficiency. The existence of an infinite number of solutions to reach the efficient frontier has led to a stream of literature on the integration of DEA and Multiple Objective Linear Programming (MOLP), which was initiated by Golany (1988).

Suzuki and Nijkamp (2007a, 2010a, and 2010b) proposed a Distance Friction Minimization (DFM) model that is based on a generalized distance friction function and serves to improve the performance of a DMU by identifying the most appropriate movement towards the efficiency frontier surface. This approach may address both an input reduction and an output increase as a strategy of a DMU. A suitable form of multidimensional projection functions is given by a Multiple Objective Quadratic Programming (MOQP) model using a Euclidean distance. A general efficiency-improving projection model including a DFM model is able to calculate either an optimal input reduction value or an output increase value to reach an efficient score of 1.0, even though in reality this may be hard to achieve.

It is noteworthy that Seiford and Zhu (2003) developed a gradual improvement model for an inefficient DMU. This 'Context-Dependent (CD)' DEA has an important merit, as it aims to reach a stepwise improvement through successive levels towards the efficiency frontier. The CD model will be used as an ingredient in the DFM model.

This paper will first design a new integrated DEA tool emerging from a blend of the DFM and CD model, namely a Stepwise DFM model, in order to design a stepwise efficiency-improving projection model for a conventional DEA. The above-mentioned stepwise-projection model is illustrated on the basis of an application to the efficiency analysis of public transport operations in Japan.

\section{Efficiency Improvement Projection in DEA: the Standard Approach}

The standard Charnes et al. (1978) model (abbreviated hereafter as the CCR-input model) for a given $\mathrm{DMU}_{j}$ $(j=1, \cdots, J)$ to be evaluated in any trial $o$ (where $o$ ranges over $1,2 \ldots, J)$ may be represented as the following fractional programming $\left(F P_{o}\right)$ problem:

$$
\left(F P_{o}\right) \quad \max _{v, u} \quad \theta=\frac{\sum_{s} u_{s} y_{s o}}{\sum_{m} v_{m} x_{m o}}
$$




$$
\begin{array}{ll}
\text { s.t. } \quad & \frac{\sum_{s} u_{s} y_{s j}}{\sum_{m} v_{m} x_{m j}} \leq 1 \quad(j=1, \cdots, J) \\
& v_{m} \geq 0, u_{s} \geq 0,
\end{array}
$$

where $\theta$ represents an objective variable function (efficiency score); $x_{m j}$ is the volume of input $m(m=1, \ldots, M)$ for DMU j $(j=1, \ldots, J) ; y_{s j}$ is the output $s(s=1, \ldots, S)$ of DMU j; and $v_{m}$ and $u_{s}$ are the weights given to input $m$ and output $s$, respectively. Model (2.1) is often called an input-oriented CCR model, while its reciprocal (i.e. an interchange of the numerator and denominator in objective function (2.1), with a specification as a minimization problem under an appropriate adjustment of the constraints) is usually known as an output-oriented CCR model. Model (2.1) is obviously a fractional programming model, which may be solved stepwise by first assigning an arbitrary value to the denominator in (2.1), and then maximizing the numerator.

The improvement projection $\left(\hat{x}_{o}, \hat{y}_{o}\right)$ can now be defined in (2.2) and (2.3) as:

$$
\begin{aligned}
& \hat{x}_{o}=\theta^{*} x_{o}-s^{-*} ; \\
& \hat{y}_{o}=y_{o}+s^{+*} .
\end{aligned}
$$

These equations indicate that the efficiency of $\left(x_{0}, y_{0}\right)$ for $\mathrm{DMU}_{0}$ can be improved if the input values are reduced radially by the ratio $\theta^{*}$, and the input excesses $s^{-*}$ are eliminated (see Figure 1). The original DEA models presented in the literature have thus far only focused on a uniform input reduction or a uniform output increase in the efficiency-improvement projections, as shown in Figure $1\left(\theta^{*}=\mathrm{OC} / \mathrm{OC}\right)$.

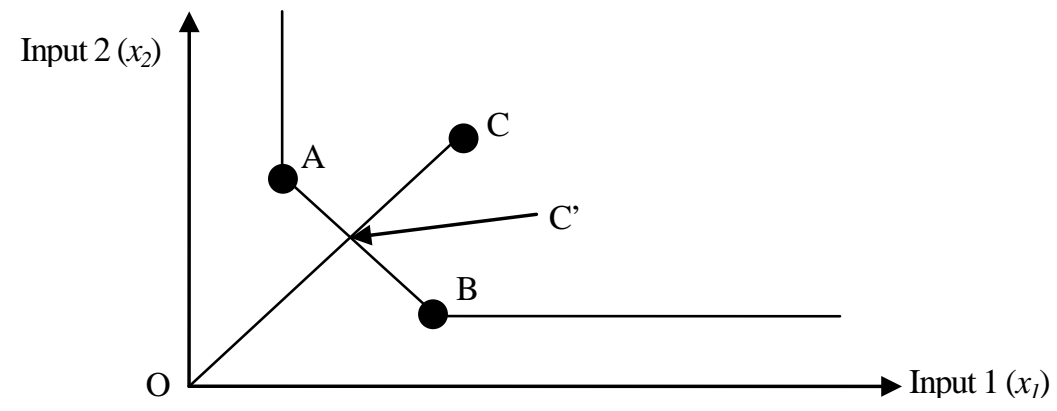

Figure 1 Illustration of original DEA projection in input space

\section{The Distance Friction Minimization (DFM) Approach}

As mentioned, the efficiency improvement solution in the original CCR-input model requires that the input values are reduced radially by a uniform ratio $\theta^{*}\left(\theta^{*}=\mathrm{OD}^{\prime} / \mathrm{OD}\right.$ in Figure 2$)$. 


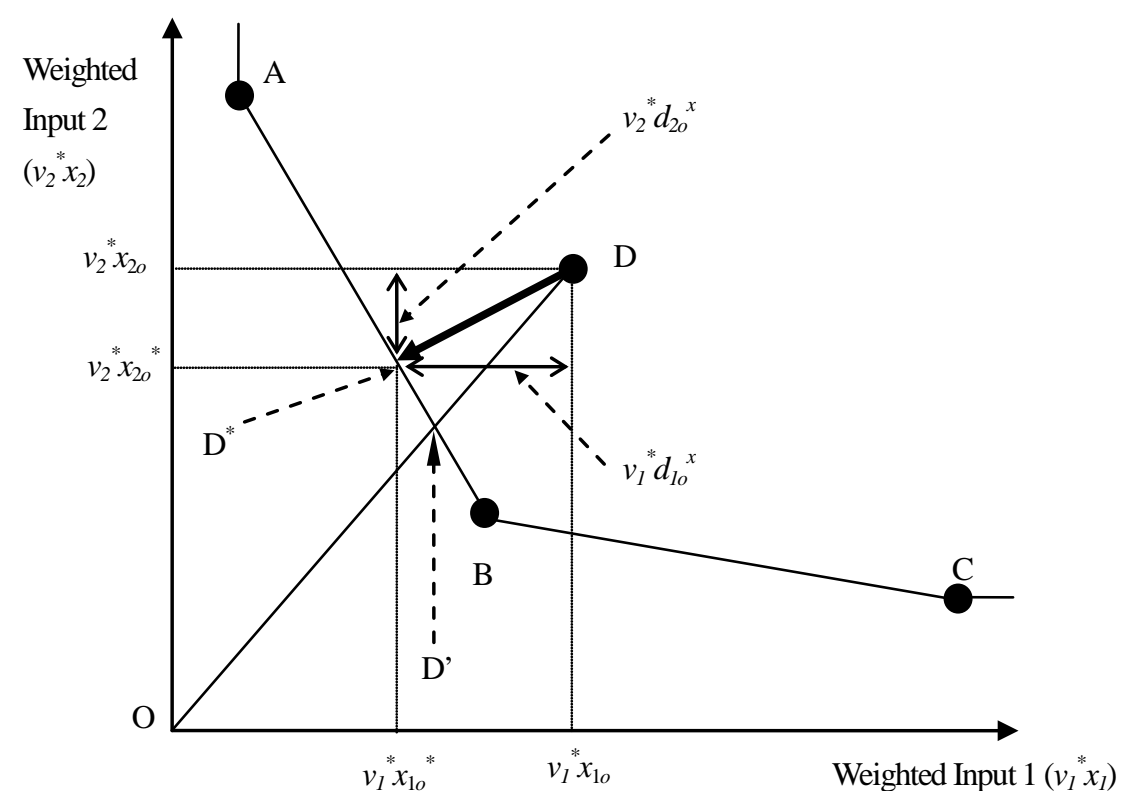

Figure 2 Illustration of the DFM approach (Input- $v_{i}^{*} x_{i}$ space)

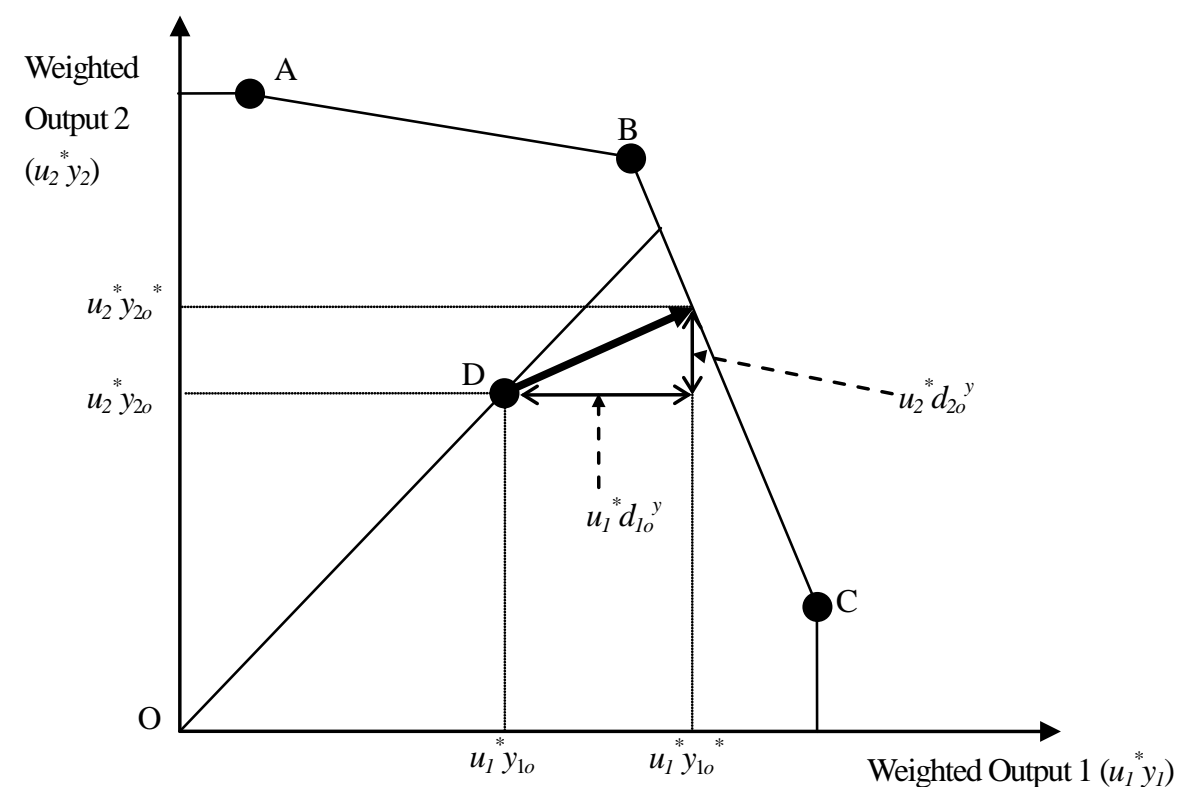

Figure 3 Illustration of the DFM approach (Output - $u_{r}^{*} \mathrm{y}_{r}$ space)

The $\left(v^{*}, u^{*}\right)$ values obtained as an optimal solution for formula (2.1) result in a set of optimal weights for $\mathrm{DMU}_{0}$. As mentioned earlier, $\left(v^{*}, u^{*}\right)$ is the set of most favourable weights for $\mathrm{DMU}_{0}$, in the sense of maximizing the ratio scale. $v_{m}{ }^{*}$ is the optimal weight for the input item $m$, and its magnitude expresses how much in relative terms the item is contributing to efficiency. Similarly, $u_{s}^{*}$ does the same for the output item $s$. These values show not only which items contribute to the performance of $\mathrm{DMU}_{0}$, but also to what extent they do so. In other words, it is possible to express the distance frictions (or alternatively, the potential increases) in improvement projections.

In this study, we use the optimal weights $u_{s}{ }^{*}$ and $v_{m}{ }^{*}$ from (2.1), and then describe next efficiency improvement 
projection model. A visual presentation of this new approach is given in Figures 2 and 3.

In this approach a generalized distance friction is deployed to assist a DMU in improving its efficiency by a movement towards the efficiency frontier surface. The direction of efficiency improvement depends of course on the input/output data characteristics of the DMU. It is now appropriate to define the projection functions for the minimization of distance friction by using a Euclidean distance in weighted spaces. As mentioned, a suitable form of multidimensional projection functions that serves to improve efficiency is given by a MOQP model which aims to minimize the aggregated input reduction frictions, as well as the aggregated output increase frictions. Thus, the DFM approach can generate a new contribution to efficiency enhancement problems in decision analysis, by deploying a weighted Euclidean projection function, and at the same time it may address both input reduction and output increase. The details of this approach have been outlined elsewhere (see Suzuki et al. 1997a, b, c). Here we will only describe the various steps concisely.

First, specify the distance friction function $\mathrm{Fr}^{x}$ and $F r^{y}$ by means of (3.1) and (3.2), which are defined by the Euclidean distance shown in Figures 2 and 3. Next, solve the following MOQP by using $d_{m o}^{x}$ (a reduction of distance for $x_{i o}$ ) and $d_{\text {so }}^{y}$ (an increase of distance for $y_{s o}$ ) as minimands in an $\mathrm{L}_{2}$ metric:

$$
\begin{array}{ll} 
& \min \mathrm{Fr}^{x}=\sqrt{\sum_{m}\left(v_{m}^{*} x_{m o}-v_{m}^{*} d_{m o}^{x}\right)^{2}} \\
& \min \mathrm{Fr}^{y}=\sqrt{\sum_{s}\left(u_{s}^{*} y_{s o}-u_{s}^{*} d_{s o}^{y}\right)^{2}} \\
\text { s.t. } \quad \sum_{m} v_{m}^{*}\left(x_{m o}-d_{m o}^{x}\right)=\frac{2 \theta^{*}}{1+\theta^{*}} \\
\quad \sum_{s} u_{s}^{*}\left(y_{s o}+d_{s o}^{y}\right)=\frac{2 \theta^{*}}{1+\theta^{*}} \\
x_{m o}-d_{m o}^{x} \geq 0 \\
d_{m o}^{x} \geq 0 \\
d_{s o}^{y} \geq 0
\end{array}
$$

where $x_{m o}$ is the amount of input item $m$ for any arbitrary inefficient $\mathrm{DMU}_{0}$, and $y_{s o}$ is the amount of output item $s$ for any arbitrary inefficient $\mathrm{DMU}_{0}$. Constraint functions (3.3) and (3.4) refer to the target values of input reduction and output increase. It is now possible to determine each optimal distance $d_{m o}^{x *}$ and $d_{s o}^{y *}$ by using the MOQP model (3.1)-(3.7). 
The friction minimization solution for an inefficient $\mathrm{DMU}_{\mathrm{o}}$ can now be expressed by means of formulas (3.8) and (3.9):

$$
\begin{aligned}
& x_{m o}^{*}=x_{m o}-d_{m o}^{x^{*}} \\
& y_{s o}^{*}=y_{s o}+d_{s o}^{y^{*}} .
\end{aligned}
$$

By means of the DFM model, it is possible to present a new efficiency-improvement solution based on the standard CCR projection. This means an increase in new options for efficiency-improvement solutions in DEA. The main advantage of the DFM model is that it yields an outcome on the efficient frontier that is as close as possible to the DMU's input and output profile (see Figure 4).

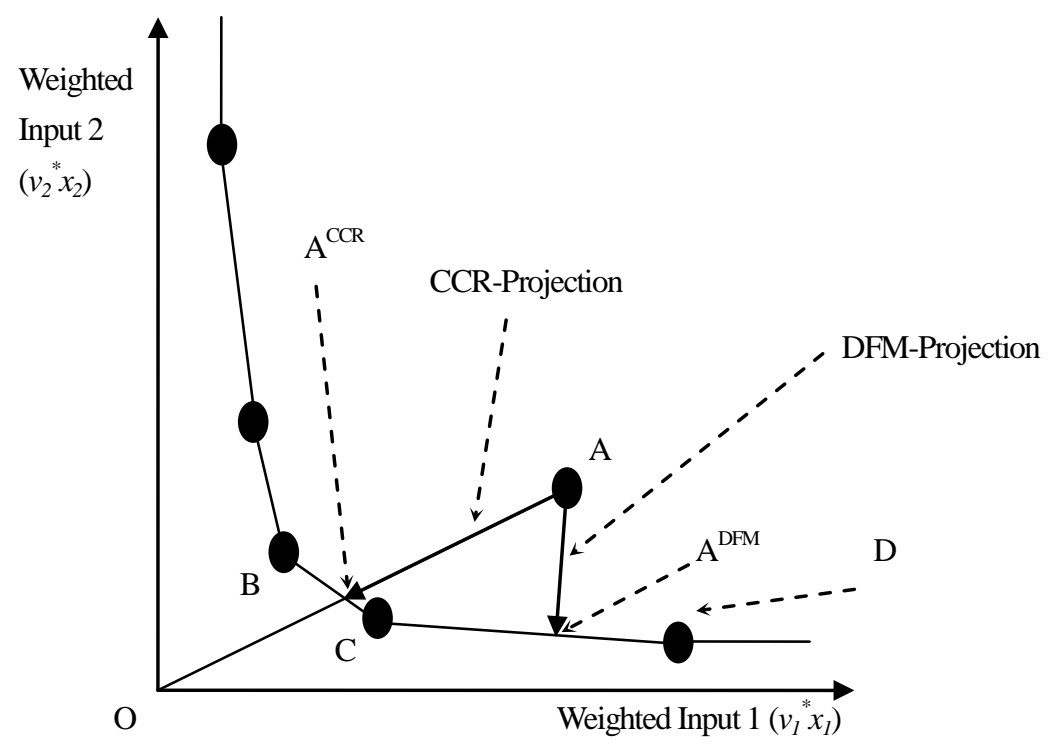

Figure 4 Degree of improvement of a DFM-projection and a CCR-projection in weighted input space

\section{Context-Dependent DEA}

The Context-Dependent (CD hereafter) model can obtain efficient frontiers in different levels, and can yield a level-by-level improvement projection. The CD model is formulated below.

Let $J^{l}=\left\{D M U_{j}, j=1, \cdots, J\right\}$ be the set of all $J$ DMUs. We interactively define $J^{l+1}=J^{l}-E^{l}$ where $E^{l}=\left\{D M U_{k} \in J^{l} \mid \theta^{*}(l, k)\right\}=1$ and $\theta^{*}(l, k)$ is the optimal value by using formula (2.2).

When $l=1$, it becomes the original CCR model and the DMUs in set E1 define the first-level efficient frontier. When $l=2$, it gives the second-level efficient frontier after the exclusion of the first-level efficient DMUs. And so on. In this manner, we identify several levels of efficient frontiers. We call Ei the lth-level efficient frontier. The following algorithm accomplishes the identification of these efficient frontiers. 
Step 1: Set $l=1$. Evaluate the entire set of DMUs, $\mathrm{J}_{1}$,. We obtain then the first-level efficient DMUs for set $\mathrm{E}_{1}$ (the first-level efficient frontier).

Step 2: Exclude the efficient DMUs from future DEA runs. $J^{l+1}=J^{l}-E^{l}$ (If $J^{l+1}=\phi$, then stop.)

Step 3: Evaluate the new subset of "inefficient” DMUs. We obtain then a new set of efficient DMUs $E^{l+1}$ (the new efficient frontier).

Step 4: Let $l=l+1$. Go to step 2 .

Stopping rule: $J^{I+1}=\phi$, the algorithm is terminated.

A visual presentation of the $\mathrm{CD}$ model is given in Figure 5.

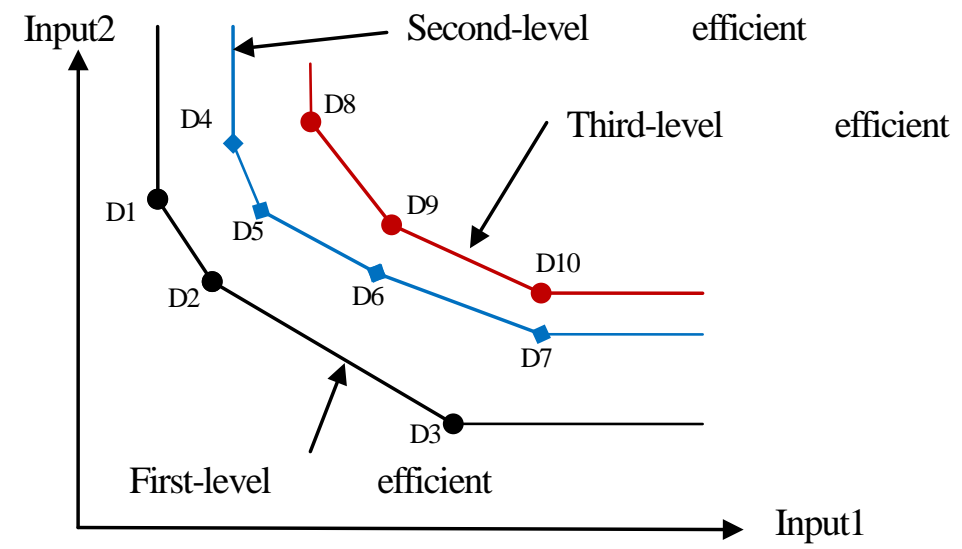

Figure 5 Illustration of the $\mathrm{CD}$ model

\section{Stepwise-DFM Model in DEA}

This section is devoted to an integration of CD and DFM models. We propose a Stepwise DFM model that is integrated with a DFM and CD model.

Any efficiency-improving projection model which includes the standard CCR projection supplemented with the DFM-projection is always directed towards achieving "full efficiency". This strict condition may not always be easy to achieve in reality. Therefore, in this section we will develop a new efficiency improving projection model, which aims to integrate with CD model and DFM approach, the "Stepwise Distance Friction Minimization" (Stepwise DFM hereafter) model. It can yield a stepwise efficiency improving projection that depends on $l$-level efficient frontiers (l-level DFM projection), as shown in Figure 6.

For example, a second-level DFM projection for DMU10 (D10) aims to position DMU10 on a second-level efficient frontier. And a first-level DFM projection is just equal to a DFM projection (3.1)-(3.7). We notice here that the second-level DFM projection is easier to achieve than a first-level DFM projection. A stepwise-DFM model can yield a more practical and realistic efficiency improving projection than a CCR Projection or a DFM Projection.

The advantage of the Stepwise DFM model is also that it yields an outcome on a $l$-level efficient frontier that is as close as possible to the DMU's input and output profile (see Figure 6). 


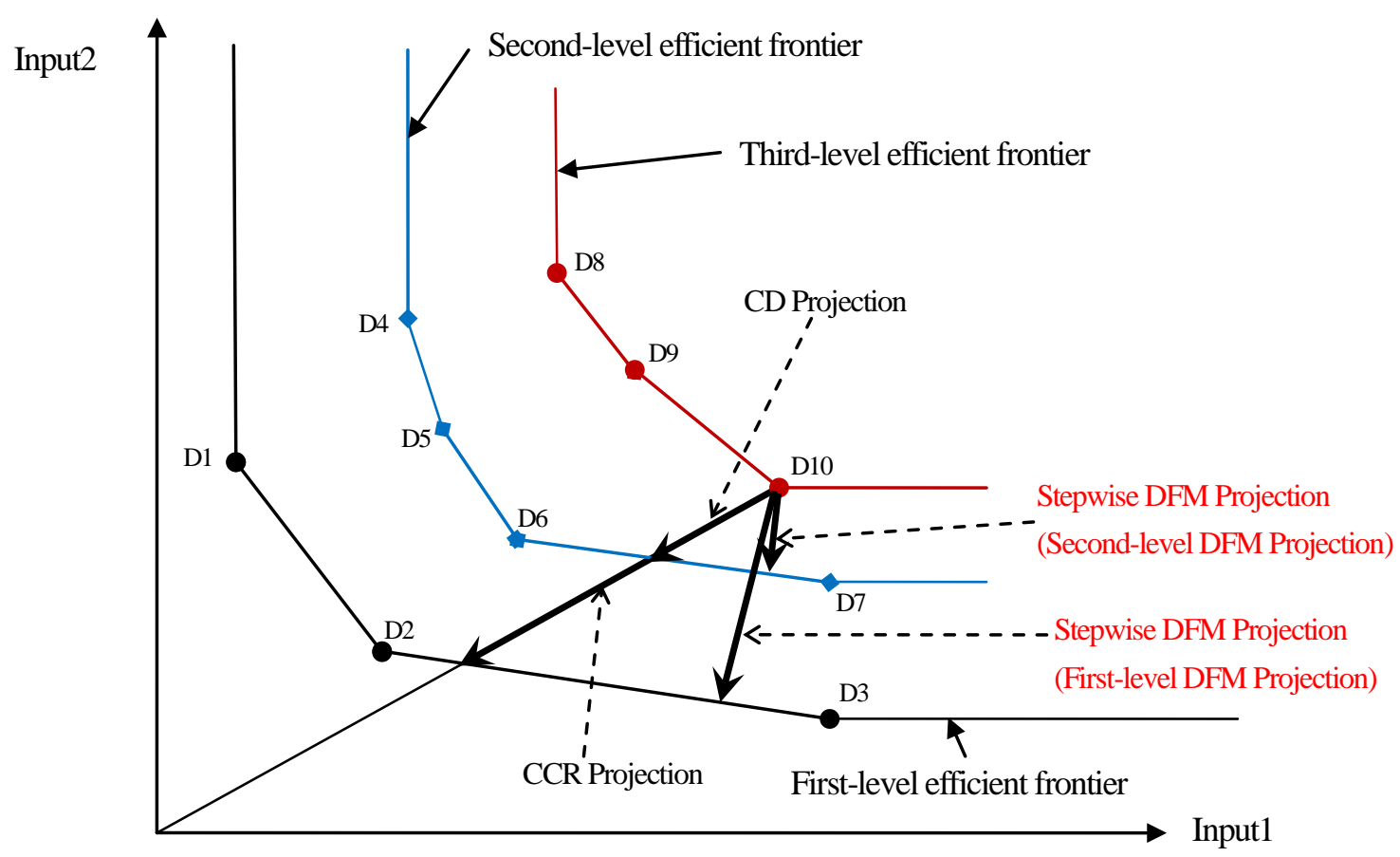

Figure 6 Illustration of the CD model

\section{Application of a Stepwise DFM Model to Public Transport Efficiency Management}

\subsection{Database and analysis framework}

In our empirical work, we use input and output data for a set of 9 urban transportation authorities and 16 major private railway companies in Japan. The DMUs used in our analysis are listed in Table 1.

Table 1 A listing of DMUs

\begin{tabular}{|c|c|c|c|}
\hline No & major private railway companies & No & urban transportation authorities \\
\hline 1 & Tobu & 1 & Sapporo \\
\hline 2 & Seibu & 2 & Sendai \\
\hline 3 & Keisei & 3 & Tokyo \\
\hline 4 & Keio & 4 & Yokohama \\
\hline 5 & Odakyu & 5 & Nagoya \\
\hline 6 & Tokyu & 6 & Kyoto \\
\hline 7 & Keikyu & 7 & Osaka \\
\hline 8 & Sotetsu & 8 & Kobe \\
\hline 9 & Meitetsu & 9 & Fukuoka \\
\hline 10 & Kintetsu & & \\
\hline 11 & Nankai & & \\
\hline 12 & Keihan & & \\
\hline 13 & Hankyu & & \\
\hline 14 & Hanshin & & \\
\hline 15 & Nishitetsu & & \\
\hline 16 & Tokyometro & & \\
\hline
\end{tabular}


In this study we use the following inputs and outputs:

- Input:

(I) Operating cost (in 2007);

(I) Railway business property (in 2007);

- Output:

(O) Operating revenues (in 2007);

All data were obtained from the "Railway annual statement 2007”. In our application, we first applied the standard CCR model, while next the results were used to determine the CCR and DFM projections. Additionally, we applied the CD model, and then the results were used to determine the CD and Stepwise DFM projections. Finally, these various results were mutually compared. The steps followed in our analysis are presented in Figure 7.

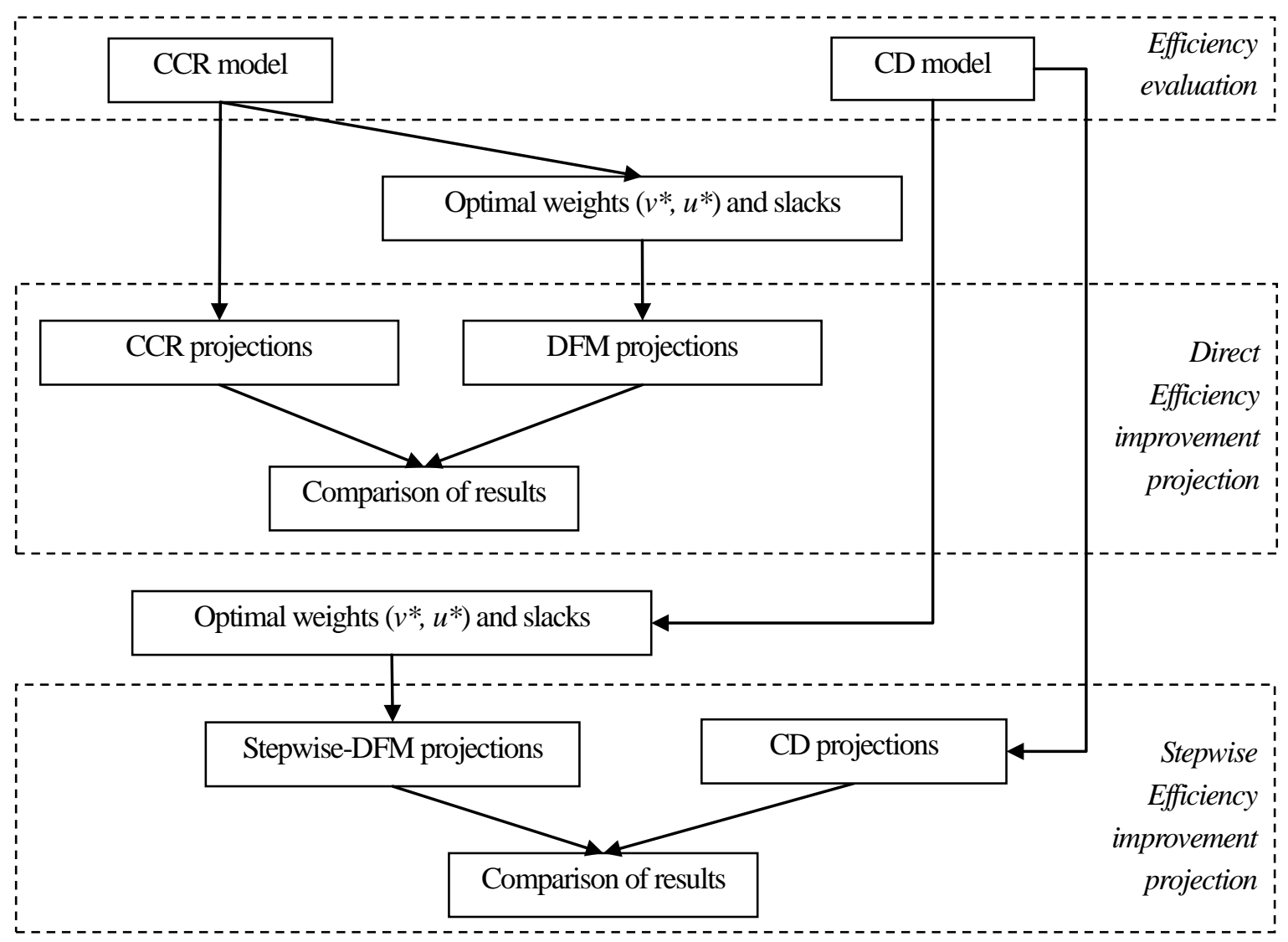

Figure 7 Analysis framework of the Stepwise DFM model

\subsection{Efficiency evaluation based on the CCR model}

The efficiency evaluation results for the 25 public transport corporations based on the CCR model is given in Figure 8. From Figure 8, it can be seen that Keio and Tokyometro are efficiently-operating corporations. On the other hand, Kyoto has a low efficiency (i.e., an efficiency score around 50 per cent). Furthermore, Kobe and Fukuoka also has a 
low efficiency.

It is noteworthy that the average efficiency level of urban transportation authorities is relatively low compared to major private railway companies. It is considered that apparently transportation authorities have still much room for further efficiently-enhancing strategies.

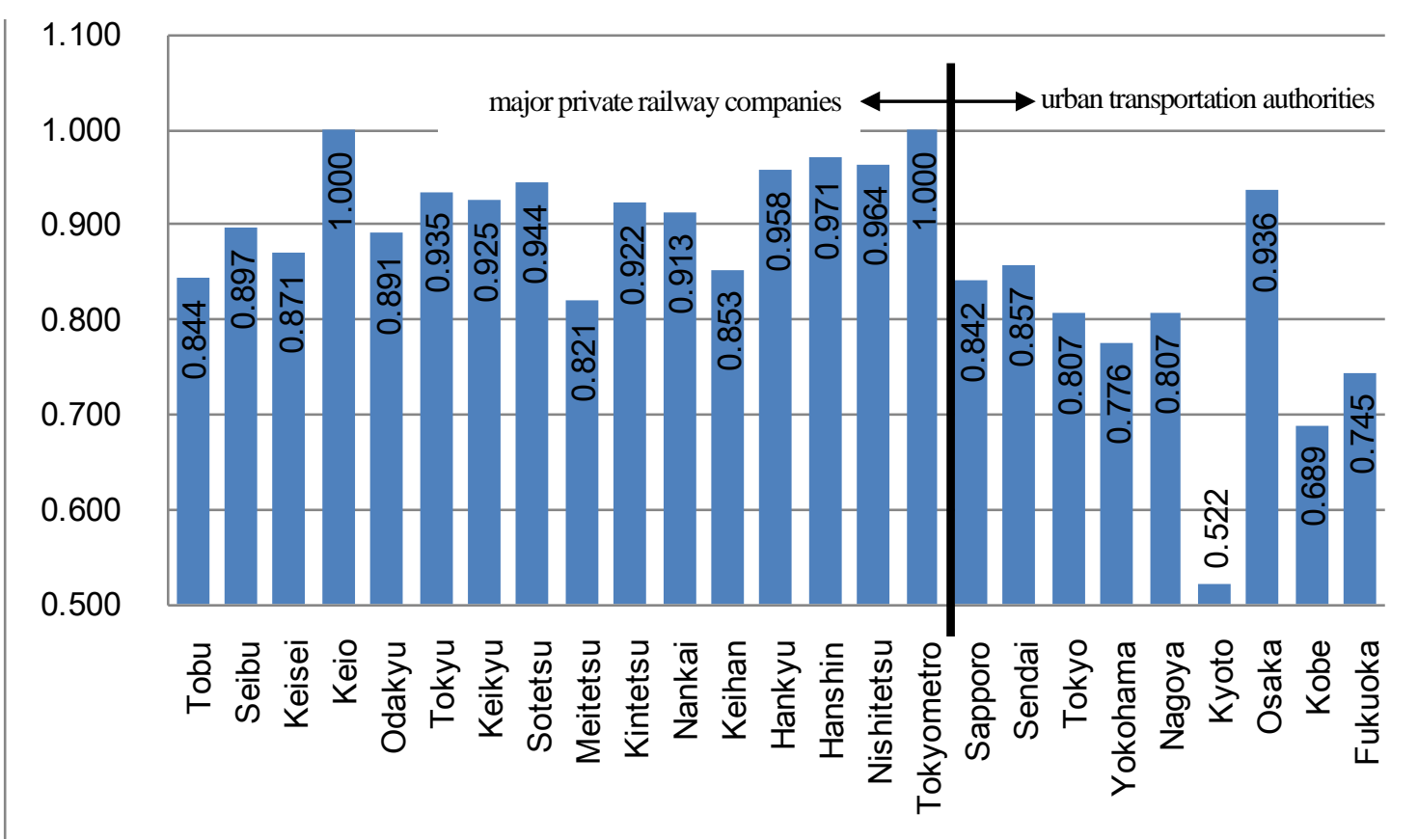

Figure 8 Efficiency score based on the CCR model

\subsection{Direct efficiency improvement projection based on the CCR and DFM models}

The direct efficiency improvement projection results based on the CCR and DFM model for inefficient public transport corporations are presented in Table 2.

In Table 2, it appears that the empirical ratios of change in the DFM projection are smaller than those in the CCR projection, as was expected. In Table 2, this particularly applies to Seibu, Tokyu, Keikyu, Hanshin and Nishitetsu, which are apparently non-slack type (i.e. $s^{-* *}$ and $s^{+* *}$ are zero) corporations. The DFM projection involves both input reduction and output increase, and, clearly, the DFM projection does not involve a uniform ratio, because this model looks for the optimal input reduction (i.e., the shortest distance to the frontier, or distance friction minimization). For instance, the CCR projection shows that Seibu should reduce the Operating cost and the Railway business property by 10.34 per cent in order to become efficient. On the other hand, the DFM results show that a reduction in Railway business property of 9.96 per cent and an increase in the Operating revenues of 5.45 per cent are required to become efficient. Apart from the practicality of such a solution, the models show clearly that a different - and perhaps more efficient - solution is available than the standard CCR projection to reach the efficiency frontier.

Table 2 Direct efficiency-improvement projection results of the CCR and DFM model 


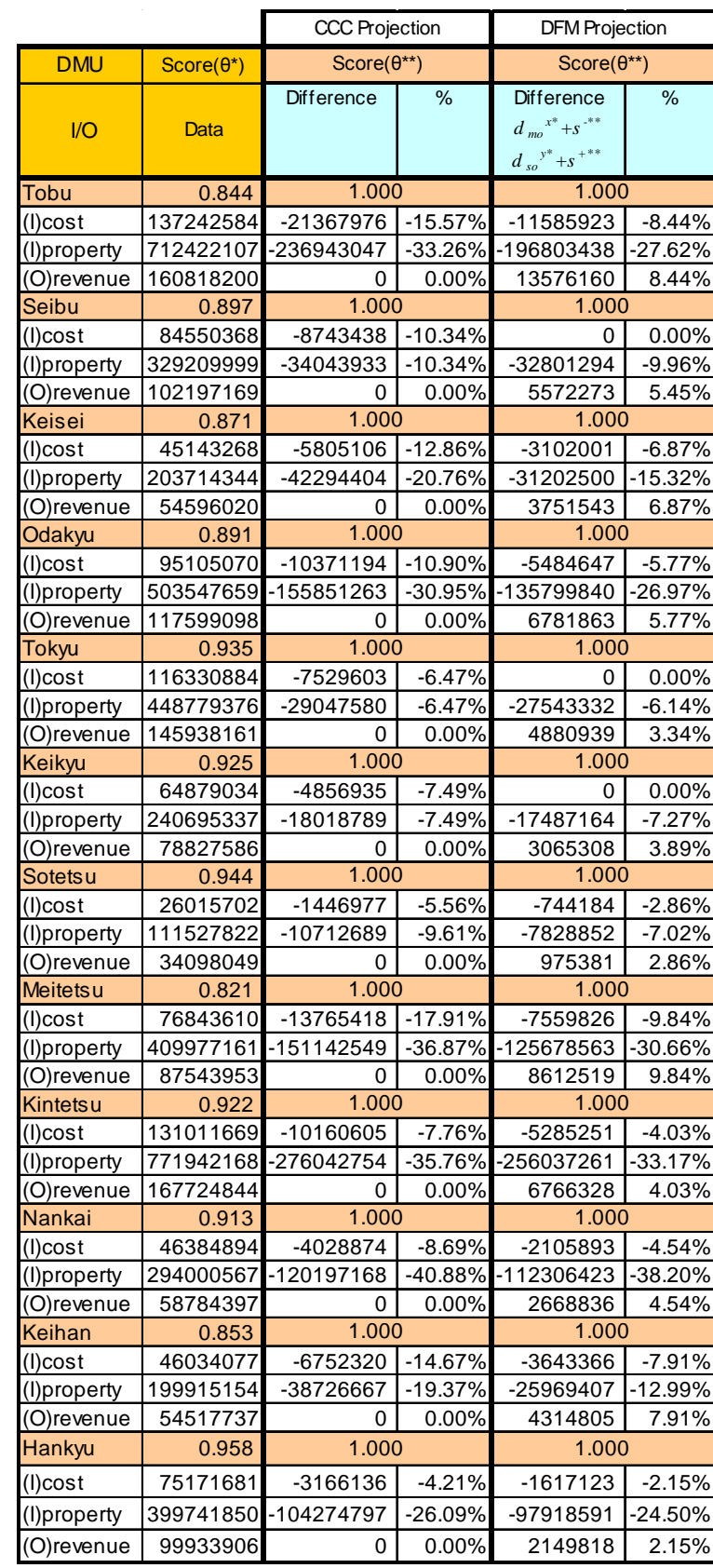

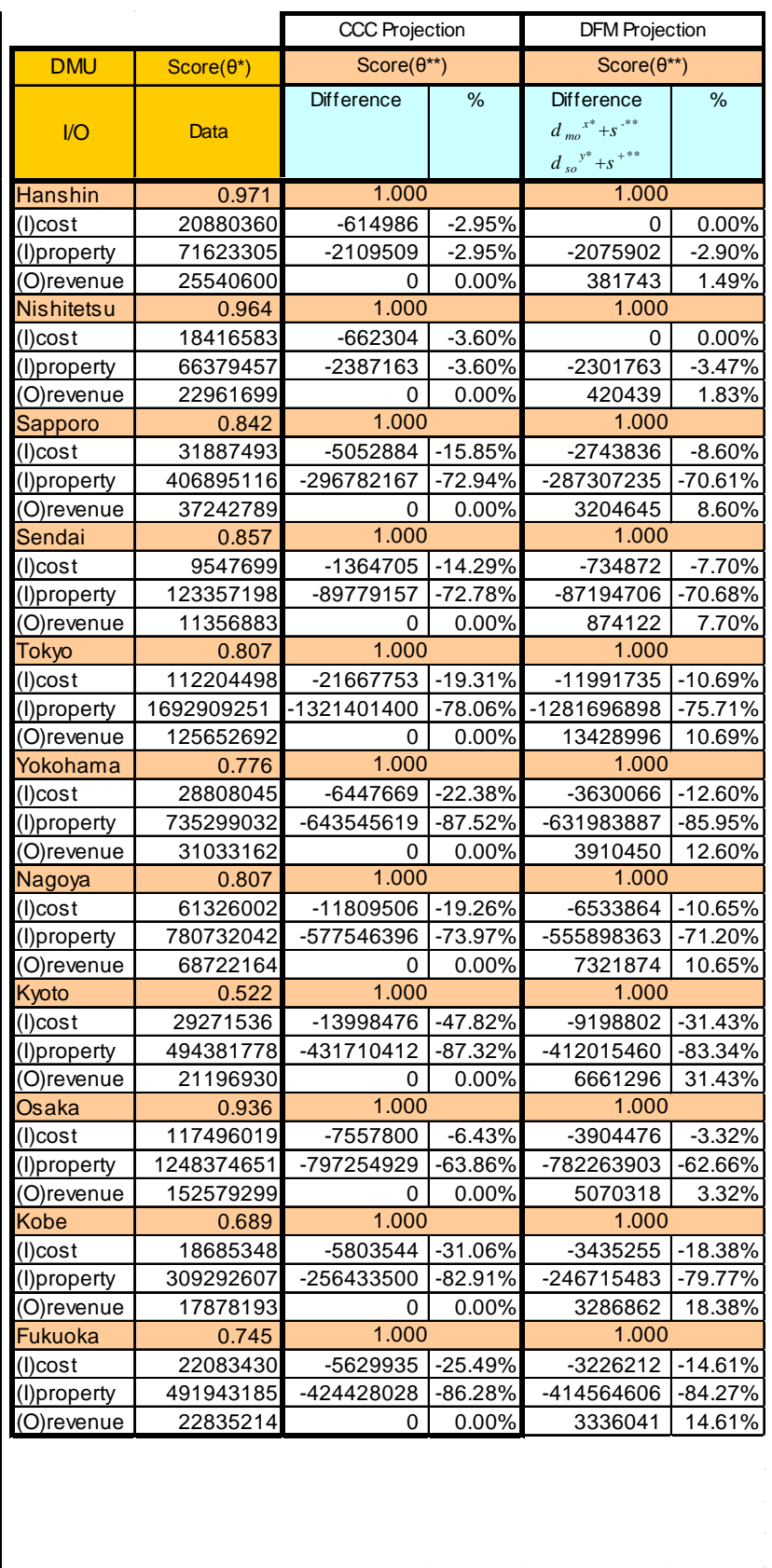

\subsection{Stepwise efficiency improvement projection based on the CD and Stepwise DFM models}

The efficiency improvement projection results for the nearest upper level efficient frontier based on the $\mathrm{CD}$ and Stepwise-DFM model for inefficient public transport corporation are presented in Table 3.

In Table 3, it appears that the ratios of change in the Stepwise DFM projection are smaller than those in the CD projection, as was expected. In Table 3, this particularly applies to Tobu, Seibu, Keisei, Odakyu, Tokyu, Keikyu, Meitetsu, Nankai, Heihan, Hanshin, Nishitetsu, Sapporo, Nagoya, and Kyoto, which are non-slack type (i.e. $s^{-* *}$ and $s^{+* *}$ are zero) corporations. Apart from the practicality of such a solution, the models show clearly that a different - and perhaps more efficient - solution is available than the $\mathrm{CD}$ projection to reach the efficiency frontier. 
Table 3 Efficiency-improvement projection results for nearest upper level efficient frontier

\begin{tabular}{|c|c|c|c|c|c|c|c|c|c|c|c|c|c|}
\hline & DMU & Score $\left(\theta^{*}\right)$ & \multicolumn{2}{|c|}{$\begin{array}{c}\text { CD } \\
\text { Projection }\end{array}$} & \multicolumn{2}{|c|}{$\begin{array}{l}\text { Stepwise-DFM } \\
\text { Projection }\end{array}$} & & \multirow{2}{*}{$\begin{array}{r}\text { DMU } \\
1 / O\end{array}$} & \multirow{2}{*}{$\begin{array}{c}\text { Score }\left(\theta^{*}\right) \\
\text { Data }\end{array}$} & \multicolumn{2}{|c|}{$\begin{array}{c}C D \\
\text { Projection }\end{array}$} & \multicolumn{2}{|c|}{$\begin{array}{l}\text { Stepwise-DFM } \\
\text { Projection }\end{array}$} \\
\hline & $1 / 0$ & Data & Difference & $\%$ & $\begin{array}{l}\text { Difference } \\
d_{m m^{* *}}+s^{-* *} \\
d_{s o} y^{*}+s^{+*}\end{array}$ & $\%$ & & & & Difference & $\%$ & $\begin{array}{l}\text { Difference } \\
d_{m m}^{x^{*}}+s^{-* *} \\
d_{s o}{ }^{y^{*}}+s^{+*}\end{array}$ & $\%$ \\
\hline \multirow{16}{*}{ E2 } & Sotetsu & 0.944 & & & & & \multirow{8}{*}{ E6 } & Tobu & 0.950 & & & & \\
\hline & (I)cost & 26015702 & -1446977 & $-5.56 \%$ & -744184 & $-2.86 \%$ & & (I)cost & 137242584 & -6805930 & $-4.96 \%$ & -4086177 & $-2.98 \%$ \\
\hline & (I)property & 111527822 & -10712689 & $-9.61 \%$ & -7828852 & $-7.02 \%$ & & (I)property & 712422107 & -35329378 & $-4.96 \%$ & 0 & $0.00 \%$ \\
\hline & (O)revenue & 34098049 & 0 & $0.00 \%$ & 975381 & $2.86 \%$ & & (O)revenue & 160818200 & 0 & $0.00 \%$ & 4088914 & $2.54 \%$ \\
\hline & Hankyu & 0.958 & & & & & & Sendai & 0.962 & & & & \\
\hline & (I)cost & 75171681 & -3166136 & $-4.21 \%$ & -1617123 & $-2.15 \%$ & & (I)cost & 9547699 & -363129 & $-3.80 \%$ & -185084 & $-1.94 \%$ \\
\hline & (I)property & 399741850 & -104274797 & $-26.09 \%$ & -97918591 & $-24.50 \%$ & & (I)property & 123357198 & -74728153 & $-60.58 \%$ & -73785469 & $-59.81 \%$ \\
\hline & (O)revenue & 99933906 & 0 & $0.00 \%$ & 2149818 & $2.15 \%$ & & (O)revenue & 11356883 & 0 & $0.00 \%$ & 220156 & $1.94 \%$ \\
\hline & Hanshin & 0.971 & & & & & \multirow{8}{*}{ E7 } & Meitetsu & 0.972 & & & & \\
\hline & (I)cost & 20880360 & -614986 & $-2.95 \%$ & 0 & $0.00 \%$ & & (I)cost & 76843610 & -2154485 & $-2.80 \%$ & -1104073 & $-1.44 \%$ \\
\hline & (I)property & 71623305 & -2109509 & $-2.95 \%$ & -2075902 & $-2.90 \%$ & & (I)property & 409977161 & -11494638 & $-2.80 \%$ & 0 & $0.00 \%$ \\
\hline & (O)revenue & 25540600 & 0 & $0.00 \%$ & 381743 & $1.49 \%$ & & (O)revenue & 87543953 & 0 & $0.00 \%$ & 1244695 & $1.42 \%$ \\
\hline & Nishitetsu & 0.964 & & & & & & Sapporo & 0.982 & & & & \\
\hline & (I)cost & 18416583 & -662304 & $-3.60 \%$ & 0 & $0.00 \%$ & & (I) $\cos t$ & 31887493 & -567949 & $-1.78 \%$ & -293748 & $-0.92 \%$ \\
\hline & (I)property & 66379457 & -2387163 & $-3.60 \%$ & -2301763 & $-3.47 \%$ & & (I)property & 406895116 & -7247223 & $-1.78 \%$ & 0 & $0.00 \%$ \\
\hline & (O)revenue & 22961699 & 0 & $0.00 \%$ & 420439 & $1.83 \%$ & & (O)revenue & 37242789 & 0 & $0.00 \%$ & 334647 & $0.90 \%$ \\
\hline \multirow{16}{*}{ E3 } & Tokyu & 0.987 & & & & & \multirow{4}{*}{ E8 } & Nagoya & 0.960 & & & & \\
\hline & (I) cost & 116330884 & -1465276 & $-1.26 \%$ & $\begin{array}{l}-1029922 \\
\end{array}$ & $-0.89 \%$ & & (I)cost & 61326002 & -2479943 & $-4.04 \%$ & -1321222 & $-2.15 \%$ \\
\hline & (I)property & 448779376 & -5652717 & $-1.26 \%$ & 0 & $0.00 \%$ & & (I)property & 780732042 & -31571779 & $-4.04 \%$ & 0 & $0.00 \%$ \\
\hline & (O)revenue & 145938161 & 0 & $0.00 \%$ & 924926 & $0.63 \%$ & & (O)revenue & 68722164 & 0 & $0.00 \%$ & 1418192 & $2.06 \%$ \\
\hline & Keikyu & 0.967 & & & & & \multirow{4}{*}{ E9 } & Tokyo & 0.999 & & & & \\
\hline & (I) cost & 64879034 & -2151905 & $-3.32 \%$ & \begin{tabular}{|l|}
-1511718 \\
\end{tabular} & $-2.33 \%$ & & (I)cost & 112204498 & -75066 & $-0.07 \%$ & -37545 & $-0.03 \%$ \\
\hline & (I)property & 240695337 & -7983371 & $-3.32 \%$ & 0 & $0.00 \%$ & & (I)property & 1692909251 & -265406432 & $-15.68 \%$ & -264928768 & $-15.65 \%$ \\
\hline & (O)revenue & 78827586 & 0 & $0.00 \%$ & 1329320 & $1.69 \%$ & & (O)revenue & 125652692 & 0 & $0.00 \%$ & 42045 & $0.03 \%$ \\
\hline & Kintetsu & 0.963 & & & & & & Yokohama & 0.962 & & & & \\
\hline & (I)cost & 131011669 & -4846697 & $-3.70 \%$ & -2469018 & $-1.88 \%$ & & (I)cost & 28808045 & -1096260 & $-3.81 \%$ & -558762 & $-1.94 \%$ \\
\hline & (I)property & 771942168 & -101032343 & $-13.09 \%$ & -88388517 & $-11.45 \%$ & & (I)property & 735299032 & -317191579 & $-43.14 \%$ & -309081955 & $-42.03 \%$ \\
\hline & (O)revenue & 167724844 & 0 & $0.00 \%$ & 3160907 & $1.88 \%$ & & (O)revenue & 31033162 & 0 & $0.00 \%$ & 601920 & $1.94 \%$ \\
\hline & Osaka & 0.977 & & & & & & Kobe & 0.854 & & & & \\
\hline & (I)cost & 117496019 & -2723737 & $-2.32 \%$ & \begin{tabular}{|l|}
-1377839 \\
\end{tabular} & $-1.17 \%$ & & (I)cost & 18685348 & -2720599 & $-14.56 \%$ & -1467105 & $-7.85 \%$ \\
\hline & (I)property & 1248374651 & -638047949 & $-51.11 \%$ & -630890840 & \begin{tabular}{|l|}
$-50.54 \%$ \\
\end{tabular} & & (I)property & 309292607 & -68421060 & $-22.12 \%$ & -49508705 & $\begin{array}{l}-16.01 \% \\
\end{array}$ \\
\hline & (O)revenue & 152579299 & 0 & $0.00 \%$ & 1789250 & $1.17 \%$ & & (O)revenue & 17878193 & 0 & $0.00 \%$ & 1403730 & $7.85 \%$ \\
\hline & Seibu & 0.963 & & & & & & Fukuoka & 0.923 & & & & \\
\hline & (I)cost & 84550368 & -3115939 & $-3.69 \%$ & -1652015 & $-1.95 \%$ & & (I)cost & 22083430 & -1692194 & $-7.66 \%$ & -879805 & $-3.98 \%$ \\
\hline & (I)property & 329209999 & -12132392 & $-3.69 \%$ & 0 & $0.00 \%$ & & (I)property & 491943185 & -184286067 & $-37.46 \%$ & -172028986 & $-34.97 \%$ \\
\hline E & (O)revenue & 102197169 & 0 & $0.00 \%$ & 1918490 & $1.88 \%$ & & (O)revenue & 22835214 & 0 & $0.00 \%$ & 909757 & $3.98 \%$ \\
\hline 54 & Nankai & 0.989 & & & & & & Kyoto & 0.753 & & & & \\
\hline & (I)cost & 46384894 & -529772 & $-1.14 \%$ & \begin{tabular}{|l|}
-271618 \\
\end{tabular} & $-0.59 \%$ & & (I) $\cos t$ & 29271536 & -7222361 & $-24.67 \%$ & -5399466 & $-18.45 \%$ \\
\hline & (I)property & 294000567 & -3357848 & $-1.14 \%$ & 0 & $0.00 \%$ & & (I)property & 494381778 & -121982117 & $-24.67 \%$ & 0 & $0.00 \%$ \\
\hline & (O)revenue & 58784397 & 0 & $0.00 \%$ & 337623 & $0.57 \%$ & & (O)revenue & 21196930 & 0 & $0.00 \%$ & 2983043 & $14.07 \%$ \\
\hline & Keisei & 0.988 & & & & & & & & & & & \\
\hline & (I)cost & 45143268 & -522332 & $-1.16 \%$ & \begin{tabular}{|l|}
-288164 \\
\end{tabular} & $-0.64 \%$ & & & & & & & \\
\hline & (I)property & 203714344 & -2357087 & $-1.16 \%$ & 0 & $0.00 \%$ & & & & & & & \\
\hline & (O)revenue & 54596020 & 0 & $0.00 \%$ & 317691 & $0.58 \%$ & & & & & & & \\
\hline & Odakyu & 0.995 & & & & & & & & & & & \\
\hline & (I)cost & 95105070 & -442591 & $-0.47 \%$ & -247053 & $-0.26 \%$ & & & & & & & \\
\hline E5 & (I)property & 503547659 & -2343361 & $-0.47 \%$ & 0 & $0.00 \%$ & & & & & & & \\
\hline & (O)revenue & 117599098 & 0 & $0.00 \%$ & 274274 & $0.23 \%$ & & & & & & & \\
\hline & Keihan & 0.971 & & & & & & & & & & & \\
\hline & (I) cost & 46034077 & -1328346 & $-2.89 \%$ & -736796 & $-1.60 \%$ & & & & & & & \\
\hline & (I)property & 199915154 & -5768692 & $-2.89 \%$ & 0 & $0.00 \%$ & & & & & & & \\
\hline & (O)revenue & 54517737 & 0 & $0.00 \%$ & 798088 & $1.46 \%$ & & & & & & & \\
\hline
\end{tabular}

The Stepwise-DFM model is able to present a more realistic efficiency-improvement plan, which we compared with the results of Tables 2 and 3. For instance, the DFM results in Table 2 show that Fukuoka should reduce the Operating cost by 14.61 per cent and the Railway business property by 84.27 per cent, an increase in the Operating revenues of 14.61 per cent in order to become efficient. On the other hand, the Stepwise DFM results in Table 3 show that a reduction in Operating cost of 3.98 per cent and Railway business property of 34.97 per cent, and an increase in the Operating revenues of 3.98 per cent are required to become efficient. The Stepwise DFM model provides the policy 
decision-maker with practical and transparent solutions that are available in the DFM projection to reach the nearest upper level efficiency frontier.

Finally, the stepwise efficiency improvement projection results for all level efficient frontiers of Kyoto (last efficiency level DMU; E11) based on the CD and Stepwise-DFM model are presented in Table 4, while a comparative result of the stepwise DFM model for Kyoto is presented in Figure 9.

Table 4 Stepwise-efficiency improvement projection results for all level efficient frontier of Kyoto City

\begin{tabular}{|c|c|c|c|c|c|c|c|}
\hline DMU & $\operatorname{Score}\left(\theta^{*}\right)$ & $\begin{array}{c}C D \\
\text { Projection }\end{array}$ & $\begin{array}{c}\text { CD-DFM } \\
\text { Projection }\end{array}$ & DMU & Score $\left(\theta^{*}\right)$ & $\begin{array}{c}\mathrm{CD} \\
\text { Projection } \\
\end{array}$ & $\begin{array}{c}\text { CD-DFM } \\
\text { Projection } \\
\end{array}$ \\
\hline I/O & Data & $\%$ & $\%$ & 1/O & Data & $\%$ & $\%$ \\
\hline E1 & 0.522 & & & E6 & 0.609 & & \\
\hline (I)cost & 29271536 & $-47.82 \%$ & $-31.43 \%$ & (I) $\cos t$ & 29271536 & $-39.12 \%$ & $-24.32 \%$ \\
\hline (I)property & 494381778 & $-87.32 \%$ & $-83.34 \%$ & (I)property & 494381778 & $-53.43 \%$ & $-42.10 \%$ \\
\hline (O)revenue & 21196930 & $0.00 \%$ & $31.43 \%$ & (O)revenue & 21196930 & $0.00 \%$ & $24.32 \%$ \\
\hline E2 & 0.545 & & & E7 & 0.620 & & \\
\hline (I) $\cos t$ & 29271536 & $-45.53 \%$ & $-29.47 \%$ & (I) $\cos t$ & 29271536 & $-38.00 \%$ & $-23.46 \%$ \\
\hline (I)property & 494381778 & $-82.85 \%$ & $-77.79 \%$ & (I)property & 494381778 & $-53.16 \%$ & $-42.17 \%$ \\
\hline (O)revenue & 21196930 & $0.00 \%$ & $29.47 \%$ & (O)revenue & 21196930 & $0.00 \%$ & $23.46 \%$ \\
\hline E3 & 0.558 & & & E8 & 0.646 & & \\
\hline (I)cost & 29271536 & $-44.24 \%$ & $-28.40 \%$ & (I)cost & 29271536 & $-35.38 \%$ & $-21.49 \%$ \\
\hline (I)property & 494381778 & $-64.92 \%$ & $-54.96 \%$ & (I)property & 494381778 & $-51.29 \%$ & $-40.82 \%$ \\
\hline (O)revenue & 21196930 & $0.00 \%$ & $28.40 \%$ & (O)revenue & 21196930 & $0.00 \%$ & $21.49 \%$ \\
\hline E4 & 0.571 & & & E9 & 0.647 & & \\
\hline (I) $\cos t$ & 29271536 & $-42.86 \%$ & $-27.27 \%$ & (I)cost & 29271536 & $-35.34 \%$ & $-21.46 \%$ \\
\hline (I)property & 494381778 & $-78.56 \%$ & $-72.71 \%$ & (I)property & 494381778 & $-42.23 \%$ & $-29.84 \%$ \\
\hline (O)revenue & 21196930 & $0.00 \%$ & $27.27 \%$ & (O)revenue & 21196930 & $0.00 \%$ & $21.46 \%$ \\
\hline E5 & 0.586 & & & E10 & 0.753 & & \\
\hline (I)cost & 29271536 & $-41.44 \%$ & $-26.13 \%$ & (I)cost & 29271536 & $-24.67 \%$ & $-18.45 \%$ \\
\hline (I)property & 494381778 & $-81.64 \%$ & $-76.84 \%$ & (I)property & 494381778 & $-24.67 \%$ & $0.00 \%$ \\
\hline (O)revenue & 21196930 & $0.00 \%$ & $26.13 \%$ & (O)revenue & 21196930 & $0.00 \%$ & $14.07 \%$ \\
\hline
\end{tabular}

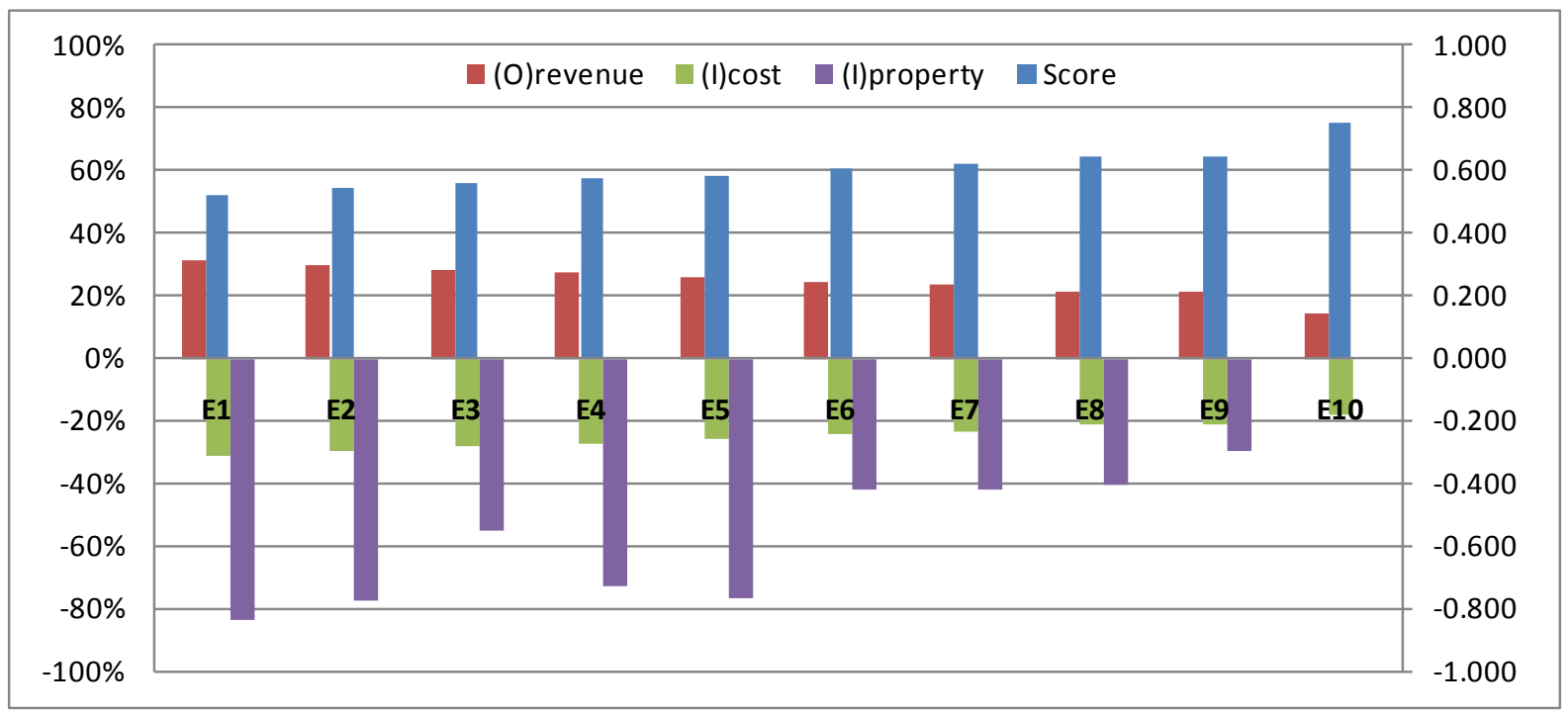

Figure 9 Efficiency improvement projection results based on the Stepwise-DFM model (Kyoto) 
The findings from Figure 9 illustrate, for instance, that, if the Kyoto city wishes to implement an efficiency improvement plan with a E10 level, only a reduction in the operating cost of 18.45 per cent and an increase in operating revenue of 14.07 per cent are required, while then the efficiency level improves to the E10 level efficient frontier.

These results offer a meaningful contribution to decision support and planning for the efficiency improvement of public transport operations. In conclusion, this Stepwise DFM model may become a policy vehicle that may have great added value for decision making and planning of both public and private actors.

\section{Conclusion}

In this paper we have presented a new methodology, the Stepwise DFM model, which is integrated with a DFM and CD model. This new methodology does not require a uniform reduction of all inputs, as in the standard model. Instead, the new method minimizes the distance friction for each input and output separately. As a result, the reductions in inputs and increases in outputs do necessarily reach an efficiency frontier that is smaller than in the standard model. This offers more flexibility for the operational management of an organization. In addition, the stepwise projection allows DMUs to include various levels of ambition regarding the ultimate performance in their strategic judgment. In conclusion, our Stepwise DFM model is able to present a more realistic efficiency-improvement plan, and may thus provide a meaningful contribution to decision making and planning for efficiency improvement of relevant agents.

\section{References}

Charnes, A., Cooper, W.W., and Rhodes, E., "Measuring the Efficiency of Decision Making Units”, European Journal of Operational Research, 2, 1978, pp. 429-444.

Golany, B., "An Interactive MOLP Procedure for the Extension of DEA to Effectiveness Analysis", Journal of the Operational Research Society, 39, 1988, pp. 725-734.

Seiford, L., A Cyber-Bibliography for Data Envelopment Analysis (1978-2005), August, 2005.

Seiford, L.M., and Zhu, J., “Context-dependent Data Envelopment Analysis - Measuring attractiveness and progress”, Omega, 31, 2003, pp. 397.

Suzuki, S., Nijkamp, P., Rietveld, P., Pels, E. “Distance Friction Minimization Approach in Data Envelopment Analysis - An Application to Airport Performance”, Paper presented at the 20th Pacific Regional Science Conference, Vancouver, 2007a.

Suzuki, S., Nijkamp, P., Rietveld, P., Pels, E. "Efficiency Improvement by Means of BCC-DFM-Fixed Factor Model in Data Envelopment Analysis - An Application to the European Airports-," European Journal of Operations Research (2010a, forthcoming)

Suzuki, S., Nijkamp, P., Rietveld, P. "Efficiency Improvement Through Distance Minimization in Data Envelopment Analysis - An Application to the Tourism Sector in Italy”, Papers in Regional Science (2010b, forthcoming) 